\title{
OS ENTRELAÇAMENTOS NA AQUISIÇÃO E USO DO LIVRO DIDÁTICO
}

\author{
LINKAGES IN THE ACQUISITION AND USE OF THE TEXTBOOK
}

\begin{abstract}
Mateus Souza de Oliveira ${ }^{1}$
RESUMO: Com o presente trabalho, objetivou-se compreender os entrelaçamentos na aquisição e no uso do livro didático, na voz dos sujeitos investigados pertencentes a um colégio estadual do interior da Bahia. Assim, esta investigação é um estudo de caso com natureza qualitativa e do tipo pesquisa exploratória. Os principais instrumentos de coleta de dados foram três questionários online, um para cada categoria, mas todos compostos por oito perguntas que buscaram conhecer a utilização do livro didático neste ambiente educacional. Os sujeitos dessa pesquisa foram seis ao todo. Os resultados mostraram que a solicitação do livro didático só acontece após a seleção democrática e o processo seletivo é uma etapa que ainda precisa ser aperfeiçoada nesse colégio. Os dados indicam também que na visão dos educandos a aquisição e utilização do livro didático facilitam os estudos, principalmente nas residências, sendo visto, por um lado, como instrumento de aprendizagem, por outro, como um simples objeto pesado disponibilizado pelo colégio que gera certo desconforto no seu deslocamento, principalmente quando não é utilizado pelo o educador durante as aulas.
\end{abstract}

PALAVRAS-CHAVE: Livro Didático. Planejamento. Instrumento de Aprendizagem.

\begin{abstract}
With the present work, the objective was to understand the entanglements in the acquisition and use of the textbook, in the voice of the investigated subjects belonging to a state school in the interior of Bahia. Thus, this investigation is a case study with a qualitative nature and exploratory research type. The main data collection instruments were three online questionnaires, one for each category, but all composed of eight questions that sought to know the use of textbooks in this educational environment. The subjects of this research were six in all. The results showed that the request for the textbook only happens after democratic selection and the selection process is a stage that still needs to be improved at this school. The data also indicate that, in the view of students, the acquisition and use of textbooks facilitate studies, especially in homes, being seen, on the one hand, as a learning tool, on the other, as a simple heavy object provided by the school that generates a certain discomfort in its displacement, especially when it is not used by the educator during classes.
\end{abstract}

KEYWORDS: Textbook. Planning. Learning Instrument.

\section{Introdução}

Realizar uma investigação que permita conhecer como estão sendo utilizados os livros didáticos, sinalizando os entrelaçamentos na sua aquisição e no uso, é uma tarefa relevante para o cenário educacional, pois, com base na análise dos dados obtidos, a equipe gestora e docente pode ter um ponto de partida que melhore o processo de ensino

\footnotetext{
${ }^{1}$ Instituto Federal de Educação, Ciência e Tecnologia da Bahia. E-mail: matheusmathica@gmail.com

(i) https://orcid.org/0000-0003-4902-5527
}

- Informações completas da obra no final do artigo 


\section{ENSIN@UFMS 2021}

ISSN 2525-7056

e aprendizagem da instituição. Isso também poderá permitir novos olhares sobre a escolha dos livros adotados.

Embora se reconheça a relevância da temática, estudos que se disponham a pesquisar as concepções, os modos de entendimento sobre os entrelaçamentos, a aquisição e uso do livro didático na voz dos sujeitos envolvidos são ainda bastante escassos no cenário educacional. Também vale ressaltar que este material de difícil definição, porém recheado de conhecimento, era um privilégio destinado, aqui no Brasil, às pessoas elitizadas com grande poder aquisitivo. Este panorama só mudou com a criação de diversas políticas públicas para o livro didático. Em outras palavras, durante o passar dos tempos, foram criados alguns programas que visaram a distribuição dos livros didáticos de forma gratuita para os educandos das redes públicas que, em sua maioria, são oriundos das classes de baixa renda familiar.

Neste contexto, é importante mostrar que o Programa Nacional do Livro Didático (PNLD), vem distribuindo milhões de livros para os educandos matriculados na Educação Básica. Atualmente, além deste programa, destaca-se, também, no âmbito dos Programas do Livro (PLi), os seguintes programas: Programa Nacional do Livro Didático para a Educação de Jovens e Adultos (PNLD-EJA); Programa Nacional do Livro Didático para o Campo (PNLD-Campo); Programa Nacional Biblioteca da Escola (PNBE) e, sobretudo, a Base Nacional Comum Curricular (BNCC).

Essa relevância atribuída ao livro didático em toda a sociedade brasileira faz com que diversas inquietações sejam consideradas. Desta forma, o presente artigo busca responder o seguinte questionamento: Quais os entrelaçamentos entre os sujeitos de um ambiente escolar na aquisição do livro didático?

À vista disso, traçamos como objetivo central: compreender os entrelaçamentos na aquisição e no uso do livro didático na voz dos sujeitos investigados pertencentes a um colégio estadual do interior da Bahia. Além disso, buscamos identificar os processos de solicitação e remanejamento dos livros didáticos; analisar o processo seletivo e a forma em que o livro didático é utilizado para o ensino; e, analisar como é a aquisição e a utilização dos livros didáticos para o processo de aprendizagem. 


\section{ENSIN@UFMS 2021}

ISSN 2525-7056

\section{O Livro Didático na Educação Pública: de 1929 aos dias atuais}

Os livros didáticos são elaborados com intuito de serem utilizados como instrumentos educacionais que tenham um caráter pedagógico para o uso individual do educando. Nessa perspectiva, visa favorecer o processo de ensino e aprendizagem. Bittencourt (2010) considera esse instrumento como o principal material didático referencial de educadores, educandos e pais, apesar dos seus dilemas. Além disso, ele é desenvolvido de acordo com as disciplinas previstas no Currículo Escolar e seus conteúdos apresentam uma sequência aparentemente rigorosa, porém cada autor explora abordagens e contextos escolares que divergem dos demais.

Para Lopes (2007, p. 208) esse instrumento é "[...] uma versão didatizada do conhecimento para fins escolares e/ou com o propósito de formação de valores [...]". Nesse espectro, configuram-se as concepções de conhecimentos dos saberes científicos, de valores éticos e morais, identidades culturais e visões de mundo. Costa e Allevato (2010, p. 2) enfatizam que o livro didático tem a função de contribuir para processo educacional sendo "[...] um interlocutor, isto é, um componente que dialoga tanto com o professor quanto com os alunos". Diante dessas perspectivas, esse material é um elo para aquisição dos conhecimentos tanto dos discentes como dos docentes.

Atualmente, no Brasil, os livros didáticos são distribuídos gratuitamente aos educandos matriculados em escolas públicas pertencentes à Educação Básica e que estão declarados no Censo Escolar. Entretanto, a história do cenário educacional brasileiro relata que este instrumento não era acessível a todos esses alunos. As distribuições dessas ferramentas surgem após a criação de algumas políticas públicas, a partir do século XIX, que focaram nas implantações de legislações que regulamentaram a produção, a circulação e o controle do livro didático.

Para Feitag, Motta e Costa (1997) o livro didático não tem uma história própria no país, assim, sinalizam que seu percurso brota de forma desordenada mediante a uma sequência de decretos, leis e medidas governamentais. Em vista disso, o Instituto Nacional do Livro (INL), criado em 1929, é o ponto inicial para este processo juntamente com criação da Comissão Nacional do Livro Didático (CNLD) que foi formada quase uma década depois. Nesse momento, é importante destacar que coexistia uma maior preocupação com o caráter político, bem como com a qualidade do que seria distribuído. Assim, buscavam 


\section{ENSIN@UFMS 2021}

ISSN 2525-7056

como objetivo a legitimação do livro didático nacional, como também incrementar a sua produção.

Por volta de 1966, o Ministério da Educação e Cultura (MEC) e a Agência NorteAmericana para o Desenvolvimento Internacional (Usaid) criaram a Comissão do Livro Técnico e Livro Didático (Colted) para coordenar, produzir, editar e distribuir milhões de livros naquele período. Desse modo, a política do livro didático foi sendo efetivada pelo Programa do Livro Didático, na década de 70, passando a ser coordenada pela Fundação Nacional do Material Escolar (Fename). Já na década seguinte, iniciou-se a distribuição desse instrumento escolar, em uma ação maior de assistência ao estudante, promovida pela então Fundação de Assistência ao Estudante (FAE).

Neste período é criado o PNLD, cuja concepção de distribuição tinha como tônica a melhoria da qualidade de ensino, bem como a formação de leitores. Esse programa trouxe diversas mudanças, entre as quais destaca-se: indicação do livro didático pelos educadores, reutilização do livro, fim da participação financeira dos estados, passando o controle do processo decisório para a FAE e extensão da oferta de livros aos educandos nas séries iniciais das escolas públicas e comunitárias. Feitag, Motta e Costa (1997) elucidam que o livro didático nacional assume durante esse período a função destinatária quase exclusiva para as crianças carentes, ou seja, alunos que são oriundos de classes populares de baixa renda familiar. Coexiste, nesse momento, uma preocupação dos governantes em combater as desigualdades sociais com a distribuição destes materiais no Ensino Fundamental.

Vale ressaltar que segundo Santos e Carneiro (2013, p. 206) "[...] o livro didático assume essencialmente três grandes funções: de informação, de estruturação e organização da aprendizagem e, finalmente, a função de guia do aluno no processo de apreensão do mundo exterior". Deste modo, este instrumento educacional deve ser capaz de promover as reflexões sobre os múltiplos aspectos da realidade e estimular a capacidade investigativa desse público.

Em 1997, com a extinção da FAE, a responsabilidade pela política de execução do PNLD foi transferida integralmente para o Fundo Nacional de Desenvolvimento da Educação (FNDE). Neste novo cenário o programa foi ampliado e passou-se a adquirir, de forma continuada, livros didáticos para todos os alunos do Ensino Fundamental público. Um ano depois o PNBE vem comprovar a ampliação da política pública do livro com a sua 
implementação. A partir de 2001, o PNLD aumentou o atendimento de forma gradativa, atendendo também aos educandos com deficiência visual, distribuindo livros em Braille, Língua Brasileira de Sinais/Libras, MecDaisy e áudio, visando à qualidade do processo educacional e à inclusão social. Assim, esses materiais em suas diversas versões foram desenvolvidos para atender, principalmente, os estudantes com deficiência visual.

Dois anos depois foi criado o Programa Nacional do Livro Didático para o Ensino Médio (PNLEM) para ser executado de maneira progressiva. Em 2004, esse programa distribuiu livros didáticos de Matemática e de Língua Portuguesa para os discentes do $1^{\circ}$ ano do Ensino Médio nas escolas públicas situadas nas regiões Norte e Nordeste. Gradativamente, os estudantes do Ensino Médio foram contemplados com livros de todos os componentes curriculares desse segmento. Com o intuito de atingir a meta de que todos os alunos matriculados no ensino fundamental possuíssem um dicionário de língua portuguesa para uso durante toda sua vida escolar, deu-se continuidade à distribuição de dicionários, bem como Atlas para as escolas que possuíssem, concomitantemente, a Educação de Jovens e Adultos (EJA) e turmas do Ensino Fundamental II. Assim, em 2009, foram instituindo o PNLD-EJA.

Como o Decreto ํㅜ 7.084, em 2010, definiu novos procedimentos para execução dos programas de material didático, assim, o PNLD ficou responsável por livros didáticos e dicionários para a Educação Básica Pública, o PNLD-EJA por livros didáticos para a Educação de Jovens e Adultos e PNBE por acervos para a Biblioteca Escolar. Como o PNLD passou a atender também o ensino médio, o PNLEM foi extinto. Em 2011, foram realizadas as aquisições e distribuições integrais dos volumes únicos e consumíveis de Inglês, Espanhol, Filosofia e Sociologia. Vale ressaltar que estes instrumentos educacionais são consumíveis, ou seja, é de um único discente. Principalmente, pela necessidade de realizar os exercícios de preencher lacunas, algo que os demais livros não têm. Isso representa que todo ano a escola recebe uma nova remessa desse material.

Nesse mesmo ano foi instituindo o PNLD-Campo, destinado a distribuir livros para as escolas de Ensino Fundamental, na área rural, que mantenham classes multisseriadas e turmas seriadas. Silva (2015, p. 135) aponta que estes instrumentos educacionais "[...] exercem grande influência na legitimação das imagens, conteúdos, códigos e formas de avaliação adotadas pelos professores das escolas localizadas nos territórios campesinos". É importante destacar que o livro didático evoluiu durante este percurso histórico. Destarte, 
Atualmente as obras didáticas estão repletas de ilustrações que parecem concorrer, em busca de espaço, com textos escritos. Ao lado dos acervos iconográficos reproduzidos nos livros, têm sido ampliadas a produção e a utilização de 'imagens tecnológicas' em vídeos e, mais recentemente, as informáticas dos softwares e dos CD-ROMs. (BITTENCOURT, 2013, p. 70).

Por exemplo, os livros de línguas estrangeiras apresentam listenings, que são exercícios de audição com o CD para os alunos usarem. A esse respeito, é importante sinalizar que o PNLD visa transformar a realidade educacional com a produção de livros de alta qualidade, quebrando o paradigma de objeto e, consequentemente, provocando no educador o desejo de transformar o contexto escolar.

Até 2018, os livros didáticos seguiam os currículos das redes e os Parâmetros Curriculares Nacionais (PCN), que orientam as disciplinas e os conteúdos a serem apresentados na escola. Ademais, existe uma relação de mercado que influencia o conteúdo. As editoras se adaptam às demandas dos educadores fornecendo, por exemplo, mais materiais com atividades para esse público. Neste contexto, no âmbito do PNLD, são distribuídos também dicionários de Língua Portuguesa, Inglesa e Espanhola, que atendem aos diversos segmentos desse nível de ensino, juntamente com materiais didáticos complementares que incluem publicações como obras clássicas e contemporâneas (de cunho histórico, econômico e cultural), de literatura brasileira, livros infanto-juvenis, obras de referência, periódicos, revistas especializadas e demais publicações de apoio a professores e alunos.

Para Lajolo (1996) o livro didático deve ser utilizado como um instrumento de aprendizagem:

Por desfrutar de uma tal importância na escola brasileira, o livro didático precisa está incluído nas políticas educacionais com que o poder público cumpre sua parte na garantia de educação de qualidade para todos. Pela mesma razão, a escolha e a utilização dele precisam ser fundamentadas na competência dos professores que, junto com os alunos, vão fazer dele (livro) instrumento de aprendizagem. (LAJOLO, 1996, p. 4)

Logo, é importante destacar que as políticas públicas vêm disponibilizando o livro didático como um material portátil gratuitamente para todos os educandos do Ensino Médio que estão matriculados nas escolas públicas cadastradas no Censo Escolar do Instituto Nacional de Estudos e Pesquisas Educacionais Anísio Teixeira (INEP). 
Por conseguinte, os colégios são beneficiados com: Livros didáticos, seriados e reutilizáveis, para $1^{\circ}$ ao $3^{\circ}$ ano, abrangendo os componentes curriculares de Língua Portuguesa, Matemática, História, Geografia, Biologia, Química e Física; Livros didáticos, seriados e consumíveis, para $1^{\circ}$ ao $3^{\circ}$ ano, abrangendo o componente curricular de Língua Estrangeira (Inglês e Espanhol); Livros didáticos, em volumes únicos e consumíveis, abrangendo os componentes curriculares de Filosofia e Sociologia; Acervos de dicionários, para uso em salas de aula de $1^{\circ}$ ao $3^{\circ}$ ano, com tipologia adequada para esta etapa.

Segundo Lajolo (1996, p. 4) "A importância atribuída ao livro didático em toda a sociedade faz com que ele acabe determinando conteúdos e condicionando estratégias de ensino, marcando de forma decisiva o que se ensina e como se ensina". E como a distribuição de livro didático pelo MEC passa necessariamente pela questão curricular, a seleção deste material realizada pelos educadores constitui uma tarefa de vital importância para uma boa utilização na aprendizagem dos educandos, principalmente, para as turmas que estão finalizando a Educação Básica.

É importante salientar que atualmente coexiste um novo PNLD para o ensino médio, ou seja, uma proposta que está ancorada as competências e habilidades elencadas na BNCC, homologada em 2018, bem como nas Diretrizes Curriculares Nacionais (DCN) que abrange toda Educação Básica. Nessa visão, serão ofertados novos livros didáticos em 2021, organizados com a proposta que firma: competências, unidades temáticas, objetos de conhecimentos e habilidades. Em síntese, o livro didático vem sendo um instrumento educacional pedagógico que historicamente está conseguindo ampliar sua oferta para os estudantes da rede pública de ensino. E esse triunfo mostra a relevância da sua aquisição bem como as finalidades para seu uso.

\section{Percurso Metodológico}

Esta investigação tem uma abordagem qualitativa, sendo classificada como um tipo de pesquisa exploratória, pois, "[...] tem como objetivo proporcionar maior familiaridade com o problema, com vistas a torná-lo mais explícito ou a construir hipóteses." (SILVEIRA; CÓRDOVA, 2009, p. 35). Nesse contexto, cabe a esse modelo de investigação levantar algumas hipóteses explicativas iniciais e apontar questões para futuras pesquisas. Contudo, é importante salientar que as hipóteses mencionadas apenas tangenciam pontos muito mais profundos e complexos que necessitam de extensas investigações. 


\section{ENSIN@UFMS 2021}

ISSN 2525-7056

Outra importante ressalva é que a pesquisa, quando realizada no campo, viabiliza as observações por meio das interações e descobertas, aproximando o investigador da realidade que está o projeto de pesquisa inserido. Dessa forma, o campo não deve ter um aspecto neutro, mas aspectos operacionais entre os referenciais teóricos e as práticas na área investigada. Por isso, no que concerne um resultado compreensivo da veracidade dos dados, tendo então em mente suas hipóteses, pressupostos propostos, interação e o conceito metodológico (MINAYO et al., 2015).

O instrumento de coleta de dados da pesquisa de campo foi o questionário online. Foram elaborados e aplicados três tipos de questionários, sendo um modelo para cada categoria. Porém, em todas foram disponibilizadas oito perguntas abertas e todas relacionadas ao objeto de estudo, para uma compreensão mais ampla da realidade do uso do livro didático.

Atualmente, a instituição investigada tem 539 alunos matriculados nos três turnos de ensino e 30 funcionários que estão divididos em equipe gestora, docente, auxiliar e de serviços gerais. Para a realização prática da pesquisa foi aplicado um questionário direcionado a um componente da equipe gestora (G1), dois da equipe docente (P1 e P2) e um discente de cada turno, matriculados no terceiro ano do colégio investigado (A1, A2 e A3). Voluntários de um convite postado nos grupos de WhatsApp da escola. Nessa lógica, esta pesquisa é composta por seis sujeitos que se voluntariaram ao saber da divulgação desta pesquisa.

Vale ressaltar que existiram outros representantes pertencentes a esse ambiente escolar que se voluntariaram e responderam o questionário. Entretanto, a pesquisa só se limitou a investigar os primeiros sujeitos de cada categoria pré-definida que enviaram as respostas questionadas. É importante destacar que foram selecionadas três equipes, pois cada uma delas se aproxima do contexto das outras. Ademais, a pesquisa adota certos procedimentos para resguardar a identidade dos sujeitos investigados, por exemplo, eles são representados por uma letra em maiúscula acompanhada de um número natural.

Foi utilizada a análise de conteúdo de Bardin (2016) para fazer verificação dos dados, passando pelo processo de estudos de pesquisas acerca das visões dos sujeitos envolvidos na solicitação/remanejamento, seleção/utilização para 0 ensino e aquisição/utilização para aprendizagem do livro didático, analisando todo material pesquisado e categorizando o conteúdo relevante para esta discussão. 


\section{Resultados e Discussão}

Inicialmente os resultados desta investigação serão apresentados em três subtítulos projetando uma análise e interpretação dos dados coletados, relacionando o tema investigado com as falas dos sujeitos envolvidos, juntamente com a discussão teórica dos estudos recentes acerca do tema. Como apresentado no delineamento metodológico, os sujeitos são identificados por G1, P1, P2 e A1, A2 e A3.

\section{A voz da gestão: remanejamento do livro didático e seus entrelaçamentos}

A questão que objetiva conhecer a solicitação e o remanejamento do livro didático e seus entrelaçamentos nos conduziu, inicialmente, para a seguinte pergunta: o colégio fazia parte do PLi? Resposta esta positiva de acordo G1 (2021). Em seguida, foi levantado outro questionamento: como é feita a escolha do livro didático? Obtivemos por esses participantes a seguinte argumentação: "Pelos professores de cada área, antes do início das aulas, a cada três anos." (G1, 2021). Dessa forma, o $G 1$ confirma que são os educadores que selecionam os livros didáticos adotados por este colégio pelo período de três anos mediante ao procedimento democrático seletivo entre os sujeitos de uma mesma área. Segundo Lajolo (1996, p. 4) "[...] a qualidade dos conteúdos do livro didático informações e atitudes - precisa ser levada em conta nos processos de escolha e adoção do mesmo, bem como, posteriormente, no estabelecimento das formas de sua leitura e uso". Foi compreendido que o livro, além de apresentar uma abordagem interessante na visão dos selecionadores, necessita ser resistente para poder durar um ciclo de três anos.

Após essa etapa, é feita, via internet, a formalização da seleção dos livros didáticos. Em seguida, são realizadas as etapas de aquisição e produção. Por fim, as editoras produzem a quantidade de livros solicitados e distribuem segundo as localidades informadas antes do período letivo, fato este evidenciado por G1 no ambiente escolar investigado. Nesse momento, infere-se que se um educador compuser o quadro de professores, após essa etapa ele deverá aceitar trabalhar com este instrumento educacional previamente selecionado. Para Bittencourt (2013, p. 72), "A complexidade da natureza desse produto cultural explica com maior precisão o predomínio que exerce como material didático no processo de ensino e na aprendizagem da disciplina, qualquer que seja 
ela." Assim, entendemos que usar um livro didático já selecionado pode gerar no educador algumas incertezas em relação ao seu método de ensino.

Em relação à questão dos professores usarem o livro didático em suas respectivas aulas, G1 apresentou a seguinte afirmação: "Para falar a verdade, pelo que percebo, são poucos os professores que usam os livros. Noto que a grande maioria trabalha com materiais pessoais, seguindo o plano do curso, mas não usam os livros adotados. Provavelmente deve ter algo que dificulte a aprendizagem do aluno." (G1, 2021). Essa argumentação revela que alguns educadores selecionam os livros didáticos, porém não usa como instrumento educacional. Isso infere que este instrumento educacional poderá não ter um significado importante para o educando, sendo tratado somente como um objeto disponibilizado pelo colégio. O G1 também enfatiza que existe uma orientação para caso o professor não queira trabalhar com o livro selecionado: "O professor deve justificar para a direção o motivo da não utilização do livro e apresentar outro tipo de recurso que colabore para seu planejamento e, sobretudo, para aprendizagem discente." (G1, 2021). Entretanto, o G1 não deixa claro se a justificativa é transmitida também aos discentes evitando que eles carreguem esse material físico para escola.

Vale ressaltar que este material em sua forma mais comum contém textos informativos que orientam a realização de exercícios e atividades que contribuem para o processo de ensino e aprendizagem. "A expectativa do livro didático é que, a partir dos textos informativos, das ilustrações, diagramas e tabelas, seja possível a resolução dos exercícios e atividades cuja realização deve favorecer a aprendizagem." (LAJOLO, 1996, p. 4).

O G1 afirma que os livros chegam para todos os educandos matriculados, porém nem todos os livros didáticos são disponibilizados para que sejam levados para suas respectivas residências. Segundo a mesma, alguns destes instrumentos educacionais são extraviados por alguns alunos, após o primeiro ano de uso, e isso consequentemente gera no próximo ano uma nova demanda. Sendo assim, coexiste a questão da quantidade de livros didáticos serem insuficiente no decorrer do tempo para a demanda discente atuante no colégio investigado.

Nessa lógica, entende-se que para evitar este problema, primeiramente, seria interessante a promoção de ações eficazes para garantir a conservação e a devolução dos livros didáticos reutilizáveis pelos educandos, inclusive mediante campanhas de conscientização 
da comunidade escolar; em segundo, registrar, no sistema específico, os dados referentes ao número de educandos matriculados no ano em curso, bem como as quantidades de livros devolvidos no ano anterior para fazer em tempo hábil os remanejamentos necessários.

\section{A Voz da Docência: seleção e utilização do livro didático para o ensino}

O educador tem a missão de adotar os recursos educacionais que facilite o alcance dos seus objetivos, porém em outros momentos é necessário adaptar estes materiais para obter êxito. Lajolo (1996, p. 6) sinaliza que "no processo de seleção do livro didático e ao longo de sua presença na sala de aula, é preciso planejar seu uso em relação aos conteúdos e comportamentos com que ele trabalha". Os dados revelados apresentam essas duas vertentes, sendo assim, logo abaixo são apresentados alguns recortes que constituem essa análise.

O sujeito P1 fez parte do processo de seleção do livro didático e selecionou os livros didáticos de suas disciplinas de acordo com a seguinte argumentação: "Infelizmente eu não recebi o guia do livro didático, a respeito disso, acredito que os demais colegas também não. Essa seleção aconteceu antes do período letivo de 2018, porém entre as dezenas de livros que existiam para serem selecionados, era ainda necessário selecionar um volume para cada ano do Ensino Médio. Como ministrava duas disciplinas fiquei com a difícil missão de opinar por seis livros, assim, fui folheando os livros buscando encontrar os aspectos que se aproximavam de uma linguagem próxima dos alunos, curiosidades sobre os conteúdos e um banco de questões que focasse nas provas do ENEM." (P1, 2021).

Já P2 informou que não pertencia ao quadro de funcionários da escola no processo de seleção do livro didático, mesmo assim utiliza o livro adotado pelos outros educadores mediante algumas adaptações e salientou que: "O livro de português adotado pela a escola é um pouco desatualizado em relação às novas discussões de Língua Materna, pois tem uma abordagem muito focada na gramática tradicional; não apresenta variedades de textos e não é adequada ao contexto dos alunos." (P2, 2021).

É importante notar que P1 inicia sua resposta informando que não recebeu o guia do livro didático, manual pedagógico que é importante para facilitar a seleção do livro didático, principalmente por apresentar as considerações de natureza teórica e metodológica sobre as componentes curriculares. Cabe ressaltar que este material, além da versão impressa 


\section{ENSIN@UFMS 2021}

ISSN 2525-7056

disponibilizada para as escolas, está sendo disponível, desde 2016, também em arquivo digital para consulta dos educadores. Infere, nesse momento, a importância de divulgar o acesso deste material, caso a versão impressa não chegue ao ambiente escolar em tempo hábil.

O educador que utiliza o guia do livro didático saberá diferenciar os livros disponíveis pelo PLi, evitando no dia do processo seletivo a perda de tempo com aqueles que divergem da sua metodologia de ensino e, consequentemente, abrindo espaço para um aprofundamento maior sobre os que se aproximam do seu planejamento escolar. Isto poderá possibilitar uma avaliação detalhada dos aspectos importantes e atinentes às práticas docentes, por meio de uma comparação entre as abordagens presente no instrumento educacional com o contexto social em que está inserido o ambiente escolar, como também permite uma visão comparativa entre o perfil dos educandos e as necessidades mais emergentes do processo de ensino e aprendizagem em relação ao componente curricular que será lecionado. Além do mais "Os capítulos selecionados, os métodos de leituras em grupos ou individual, assim como as tarefas decorrentes da leitura são opções exclusivas do professor, mesmo quando inseridas ou limitadas por projeto pedagógico estipulado pela a escola." (BITTENCOURT, 2013, p. 74). Ou seja, tudo depende do planejamento docente.

Outro episódio relevante está na argumentação de P2 ao evidenciar que o livro adotado para o ensino da sua componente curricular está desatualizado, pois este fato é uma realidade em muitos livros didáticos disponíveis no cenário educacional brasileiro. Dessa forma, depreende-se a necessidade de analisar todas as abordagens do material instrumental antes do planejamento das aulas. Segundo Lajolo (1996, p. 7) "[...] o livro didático ruim exige que o professor interfira de forma sistemática nos conteúdos e atividades propostas e consideradas inadequadas.". Em sala de aula é importante enfatizar os erros presentes no livro didático adotado, mostrando que nem sempre ele apresenta um conteúdo eficiente, coerente e atual. É interessante também trabalhar diferentes posicionamentos sobre a temática que pode levar os educandos até novos olhares sobre 0 que é abordado no material em uso. É importante sinalizar que P2 não adota o livro didático de forma única e exclusiva para o ensino de sua componente curricular. Assim, ela evita a tendência de ser refém somente deste instrumento adotado por outros educadores com exclusividade para seus planejamentos e ensinamentos. Cabe ressaltar que Lajolo (1996) 
também aponta que o livro didático bom, apropriado e coerente, também necessita que o educador personifique o uso para as práticas docentes em sala de aula.

Evidenciamos também mediante as outras argumentações desses sujeitos que alguns conteúdos apresentados pelo livro didático adotado aparecem de forma superficial e distante da realidade cultural do educando. Isso pode conduzir os educandos a um rol de informações muitas vezes incorretas ou incompletas. Diante dessa perspectiva, nota-se a necessidade dos educadores colocarem em prática suas autonomias, para tentar filtrar os conteúdos e encontrar os suportes que irão ser veiculados ou adaptados às necessidades do ensino e aprendizagem. Também mostra que o livro didático não pode ser visto como a única fonte de conhecimento, mas como um instrumento de aprendizagem.

Para tanto, a seleção do livro didático necessita ser fundamentada nas habilidades e competências dos educadores e focar no desenvolvimento dos seus discentes no intuito de transformar esse objeto em um instrumento educacional que facilite o processo de ensino e aprendizagem. Sem esquecer que "É preciso levar em consideração as especificidades sociais e culturais da comunidade em que o livro é utilizado, para que o seu papel na formação integral do aluno seja mais efetivo" (BRASIL, 2007, p. 12).

\section{A Voz dos Educandos: aquisição e utilização do livro didático para aprendizagem}

Nesse momento a presente pesquisa foca atenção para a voz dos educandos em relação à aquisição e utilização do livro didático. Iniciamos este momento mediante as descrições de A1, aluno do turno matutino, que relatou que os livros didáticos apresentam uma linguagem complicada que só é compreendida por meio da mediação do educador. Isso mostra que estes instrumentos ainda estão longe da contextualização educacional de cada região. Nesta perspectiva A1, elucida que o livro didático: "É um pouco complicado, mas os professores nos ajudam a entender os conteúdos dos livros. Vejo algumas coisas interessantes nos livros e sei que é através deles que surge a aprendizagem. Gosto quando os professores usam os livros, pois não precisa escrever muito e é mais prático para estudar para as provas." (A1, 2021).

Diante dessa descrição, conclui-se que a aquisição do livro didático é um instrumento de aprendizagem de suma importância no estudo das avaliações. Assim, entende-se que pode ser o único recurso disponível para alguns educandos para essa etapa. Além disso, nota-se que a utilização do livro didático evita a perda de tempo com a transposição do que 
é apresentado na lousa para o caderno. Outro ponto importante observado nesta descrição é que o livro didático pode despertar o educando para aquisição de novos conhecimentos por meio de suas diversas linguagens, ou seja, "[...] a partir dos textos informativos, das ilustrações, diagramas e tabelas, seja possível a resolução dos exercícios e atividades cuja realização deve favorecer a aprendizagem." (LAJOLO, 1996, p. 5).

Já no período vespertino foi verificado nas descrições de A2 que os livros didáticos são recursos que desempenham papéis essenciais no processo educativo, sendo utilizados pelos educandos como um dos instrumentos de aprendizagem. Isto infere a possibilidade do preenchimento de lacunas que não foram contempladas nas salas de aulas, como também a possibilidade abrir os olhares para novas dimensões e minimizar as complexidades ao redor das abordagens exploradas. Desta forma, A2 elucida que os livros didáticos são: "Bem úteis, temos mais informações sobre os temas estudados. Neles encontro o que não deu tempo de conhecer no colégio. Em casa a curiosidade aumenta e tendo acesso ao livro em casa, é possível explorar com mais tempo. E o aprendizado se torna maior." (A2, 2021). Essa descrição apresenta a importância da aquisição do livro didático como instrumento portátil que pode ser consultado em outros locais que não seja um ambiente educacional. Além disso, ele é utilizado como instrumento de aprendizagem que guia o educando para minimizar as dúvidas e gerar novos conhecimentos. Depreendese que, deste modo, o livro didático pode conduzir os educandos ao domínio progressivo de uma determinada abordagem curricular. Conforme Bittencourt (2013) os usos que educadores e educandos fazem do livro didático são variados e isso pode promover um trabalho eficiente e adequado às necessidades de um processo de ensino e aprendizagem com qualidade.

No período noturno, constatamos nas descrições de A3 que poucos educadores utilizam os livros didáticos disponibilizados pelo colégio. Além disso, notou-se que o livro é empregado de forma estimulante, mas é feito de modo superficial. Dessa forma, entendese que a interpretação, a reflexão e a visão crítica dos conteúdos apresentados nestes recursos didáticos não são exploradas como deveriam ser.

Em meio a umas das perguntas A3 acrescenta: "Como eu disse, quase ninguém usa esses livros, quando é utilizado é para fazer um resumo. No geral, levamos estes livros só para doer as costas. Assim, eles fazem mais moradia aqui em casa do que no colégio." (A3, 2021). Essa descrição além de certificar o que foi referido no parágrafo anterior, mostra 
outra consequência que não é o foco desta pesquisa, porém é importante ressaltar já que é um tema de diversas pesquisas nas escolas do Ensino Fundamental I, ou seja, o excesso de peso ocasionado por esses objetos prejudicam a coluna, afetando a postura. Assim, conclui-se que para evitar problemas de desgastes físicos, os livros didáticos acabam sendo conservados na residência.

É importante salientar que o livro didático, nesse último contexto, não apresenta uma aquisição eficiente para o educando, como também não permite uma aprendizagem de qualidade, já que para eles, este instrumento não passa de um simples objeto pesado que ocupa um espaço na residência ou serve para transposição de pequenos trechos de textos para o caderno. Contudo, salienta-se que esse pode ser um dos principais "[...] instrumento de trabalho de professores e alunos, sendo utilizado nas mais variadas salas de aula e condições pedagógicas, servindo como mediador entre a proposta [...] nos programas curriculares e o conhecimento escolar ensinado [...]" (BITTENCOURT, 2013, p. 72). Diante dessa perspectiva, o livro didático precisa ser explorado de acordo com suas reais finalidades para que sua clientela compreenda a importância desse instrumento que atualmente busca desenvolver competências relevantes para formação de um cidadão.

\section{Considerações Finais}

Pode-se concluir que a ideia de compreender os entrelaçamentos na aquisição e no uso do livro didático na voz dos sujeitos investigados, mostrou-se oportuna por proporcionar a visibilidade das opiniões dos sujeitos diretamente envolvidos que são, provavelmente, os maiores interessados na utilização deste instrumento educacional. Em síntese, as falas dos participantes possibilitaram a categorização e ofereceram subsídios que auxiliaram para alcançar os objetivos traçados. Assim, a pesquisa mostrou que a solicitação do livro didático só acontece após a seleção democrática do mesmo que é realizada pelos educadores de cada área. Além do mais, o remanejamento é uma realidade neste ambiente investigado, já que os livros são extraviados por alguns educandos nos últimos anos em que período de uso é válido.

O processo seletivo do livro didático para o ensino evidenciou que esta etapa ainda precisa ser aperfeiçoada. Além disso, existe a necessidade dos educadores colocarem em prática suas autonomias, para tentar filtrar os conteúdos abordados por esse instrumento educacional, numa perspectiva de encontrar os suportes que irão ser veiculados ou 


\section{ENSIN@UFMS 2021}

ISSN 2525-7056

adaptados aos planejamentos traçados. A aquisição e utilização do livro didático pelos educandos revelou que ele é visto como instrumento aprendizagem que facilita os estudos, principalmente nas residências, local em que deverá ser o palco das revisões sobre as abordagens discutidas em sala de aula. Entretanto, é também visto como um simples objeto disponibilizado pelo colégio que gera certo desconforto no seu deslocamento quando não é utilizado pelo educador.

Portanto, os entrelaçamentos na aquisição e no uso do livro didático geram reflexões sobre a importância deste instrumento de aprendizagem, principalmente na forma adequada para selecionar, solicitar, utilizar e explorar. Além disso, é o ponto primordial que todos os educandos sejam contemplados e orientados como utilizar estes recursos de forma saudável, prazerosa e como uma fonte de conhecimento. Durante essas investigações surgiram novas reflexões que poderão ser objetos de novas pesquisas, entre as quais destaco: a forma como cada educador utiliza o livro didático para suas aulas; as dificuldades encontradas na utilização do livro didático como instrumento de aprendizagem; os métodos mais eficientes na utilização do livro didático em sala de aula e fora dela.

\section{Referências}

BARDIN, L. Análise de Conteúdo. Lisboa, Portugal: Edições 70, 2016.

BITTENCOURT, C. M. F. Livros didáticos entre textos e imagens. In: BITTENCOURT, C. (Org.). O saber histórico na sala de aula. 11. ed. São Paulo: Contexto, 2010. p. 69-90.

BITTENCOURT, C. M. F. O saber histórico na sala de aula. 12. ed. São Paulo: Contexto, 2013.

BRASIL. Decreto $\mathbf{n}^{\circ} \mathbf{7 . 0 8 4}$, de 27 de janeiro de 2010. Dispõe sobre material didático e dá outras providências, Brasília, DF: Ministério da Educação, 2010. Disponível em:

http://www.planalto.gov.br/ccivil_03/_ato2007-2010/2010/decreto/d7084.htm. Acesso em: 29 nov. 2021.

BRASIL. Guia de livros didáticos: PNLD 2007. Brasília, DF: Ministério da Educação, 2007. Disponível em: https://www.gov.br/fnde/pt-br/acesso-a-informacao/acoes-eprogramas/programas. Acesso em: 29 nov. 2021.

COSTA, M.S; ALLEVATO, N. S. G. Livro didático de Matemática: análise de professores polivalentes em relação ao ensino de Geometria. Revista Vidya, Santa Maria, v. 30, n. 2, p. 71-80, jul./dez., 2010. Disponível em:

https://periodicos.ufn.edu.br/index.php/VIDYA/article/viewFile/312/285. Acesso em 23 nov. 2021. 


\title{
ENSIN@UFMS 2021
}

FREITAG, B; COSTA, W. F.; MOTTA, V. R. O livro didático em questão. 3. ed. São Paulo: Cortez, 1997.

LAJOLO, M. Livro didático: um (quase) manual de usuário. Em Aberto, v. 16, n. 69, p. 39, jan./mar., 1996. Disponível em:

http://emaberto.inep.gov.br/index.php/emaberto/article/view/2061/2030. Acesso em: 29 nov. 2021.

LOPES, A.C. Currículo e epistemologia. Ijuí, RS: Editora Unijuí, 2007.

MINAYO, M. C. S. (Org.) et al. Pesquisa social: teoria, método e criatividade. 34. ed. Petrópolis, RJ: Vozes, 2015.

SANTOS, W. L. P; CARNEIRO, M.H.S. Livro didático de ciências: fonte de informação ou apostila de exercícios? Contexto \& Educação, Ano 21, n. 76, p. 201-222. jul./dez., 2013. Disponível em:

https://www.revistas.unijui.edu.br/index.php/contextoeducacao/article/view/1103. Acesso em: 29 nov. 2021.

SILVA, F. G. P. Os paradigmas que alicerçam os livros didáticos de história e geografia da coleção didática projeto buriti multidisciplinar: um olhar através das epistemologias do sul. Dissertação (Mestrado em Educação Contemporânea). Universidade Federal de Pernambuco. Caruaru, p. 305, 2015.

SILVEIRA, D. T; CÓRDOVA, F. P. A pesquisa científica. In: GERHARDT, T.E.; SILVEIRA, D.T. (Org.). Métodos de pesquisa. Porto Alegre, RS: Editora da UFRGS, 2009.

\section{NOTAS}

\section{IDENTIFICAÇÃO DE AUTORIA}

Mateus Souza de Oliveira. Mestre em Educação Matemática pela Universidade Estadual de Santa Cruz (UESC). Professor EBTT do Instituto Federal de Educação, Ciência e Tecnologia da Bahia (IFBA). Bahia, Brasil.

E-mail: matheusmathica@gmail.com

(i) https://orcid.org/0000-0003-4902-5527

\section{AGRADECIMENTOS}

Não se aplica.

\section{FINANCIAMENTO}

Não se aplica.

\section{CONSENTIMENTO DE USO DE IMAGEM}

Não se aplica.

\author{
APROVAÇÃO DE COMITÊ DE ÉTICA EM PESQUISA \\ Não se aplica.
}

\section{LICENÇA DE USO}


Autores mantêm os direitos autorais e concedem à revista ENSIN@ UFMS - ISSN 2525-7056 o direito de primeira publicação, com o trabalho simultaneamente licenciado sob a Licença Creative Commons Attribution (CC BY-NC-SA 4.0), que permite compartilhar e adaptar o trabalho, para fins não comerciais, reconhecendo a autoria do texto e publicação inicial neste periódico, desde que adotem a mesma licença, compartilhar igual.

\section{EDITORES}

Patricia Helena Mirandola Garcia, Eugenia Brunilda Opazo Uribe, Gerson dos Santos Farias.

\section{HISTÓRICO}

Recebido em: 09/08/2021 - Aprovado em: 30/11/2021 - Publicado em: 06/12/2021.

\section{COMO CITAR}

OLIVEIRA, M. S. Os Entrelaçamentos na Aquisição e Uso do Livro Didático. Revista ENSIN@ UFMS, Três Lagoas, v. 2, n. 6, p. 221-238. 2021. 